\title{
Arte e inclusão
}

\author{
Morgana Tesman
}

\begin{abstract}
Diante de novas possibilidades educacionais, a escola tenta se aproximar da teoria e da legislação brasileira que indica a inclusão escolar de portadores de necessidades educativas especiais no ensino regular. Das observações retiradas de uma prática de estágio em artes plásticas, concluiu-se que com um pouco de esforço a inclusão pode virar uma realidade
\end{abstract}

A inclusão de deficientes no ensino regular: será que isto pode dar certo? Como fazer com que uma criança ou adolescente socialmente rotulado "diferente" sinta-se realmente inserido no meio escolar como os seus pares? Como conduzir uma prática pedagógica em arte que traduza melhor as aspirações de uma sala de aula não segregativa?

Por educação inclusiva entende-se a prática escolar que inclua o portador de necessidades educativas especiais na sala de aula do ensino regular. Para tanto, a escola precisa estar equipada e preparada tanto física quanto profissionalmente.

O MEC Ministério da Educação editou em 1999 os Parâmetros Curriculares Nacionais PCN (BRASIL, 1999) com adaptações curriculares para educação de alunos com Necessidades Educativas Especiais NEE. Neste documento são traçados os objetivos do movimento nacional da "educação para todos", sugerindo as adaptações curriculares necessárias para o atendimento destes alunos em classes comuns do ensino regular.

Também o texto do capitulo $V$ da Lei de Diretrizes e Bases da Educação Nacional (LDBEN) $n^{\circ}$ 9394/96 diz em seu artigo 58 que "entende-se por educação especial, para os efeitos desta Lei, a modalidade de educação escolar, oferecida 
preferencialmente na rede regular de ensino, para educandos portadores de necessidades especiais" (BRASIL, 1997). Com isso, percebe-se que a legislação brasileira já prevê há alguns anos a inclusão de alunos portadores de NEE no ensino regular.

Mas, na realidade das classes escolares, esta legislação pode ser aplicada?

Através da realização de um estágio curricular supervisionado, disciplina do curso de licenciatura em Artes Plásticas da UDESC Universidade do Estado de Santa Catarina - foi possível observar e atuar com artes plásticas numa escola da Rede Pública Municipal de Florianópolis, que há cerca de dois anos vem trabalhando no sentido de se adaptar à nova legislação brasileira. 0 que se observou nesta experiência é que a prática está ainda muito distante da teoria e da legislação. Existem alguns livros e textos publicados embasando e exemplificando situações da prática inclusiva em escolas do Brasil e de várias partes do mundo, mas esta bibliografia não chega, ao menos na escola observada, nem nas mãos dos professores, equipe pedagógica ou direção, nem dos pais, comunidade ou demais colaboradores da escola.

No entanto, a principal parte do processo já está presente, os alunos portadores de NEE já freqüentam (e enfrentam) os bancos escolares com muita coragem.

Uma renovação deste porte, obviamente, encontra obstáculos principalmente culturais e administrativos, já que é difícil pensar em mudanças e praticá-las diante de todos os impedimentos financeiros que as escolas apresentam no Brasil. Corre-se o risco dos profissionais rotularem suas práticas atuais como 
"inclusivas", apenas por terem um aluno especial em sua classe regular, sem nada modificar sua didática de ensino.

O projeto apresentado para o estágio curricular tinha como objetivo principal o uso das artes como um instrumento de inclusão. Especificamente, objetivava utilizar a linguagem plástica da construção tridimensional como mote para a apreciação, o fazer e a contextualização artística, sempre com a meta da inclusão norteando as atividades.

O campo de estágio foi escolhido em função da possibilidade de se atuar em uma turma que apresentasse algum aluno portador de NEE. A escola escolhida foi a Escola Municipal Doutor Paulo Fontes, no bairro de Santo Antônio de Lisboa, em Florianópolis.

A atuação foi realizada em uma turma de 33 alunos da $4^{a}$ série do ensino fundamental, período vespertino, com faixa etária variando de 9 a 14 anos, todos eles moradores da comunidade de Santo Antonio e adjacências (Cacupé e Sambaqui).

0 que se pode perceber, durante o período de observação é que os alunos, todos de classe média baixa, apresentavam baixo rendimento escolar, dificuldades de leitura e compreensão de texto escrito. Por outro lado se mostraram participativos quando o tema da aula lhes era familiar. Falantes, irrequietos e agitados, como é comum a jovens desta faixa de idade. Mostraram-se muito receptivos quanto à presença de uma estagiária em classe.

O jovem portador de NEE, aqui chamado Paulo com 14 anos completos, se destacava dos demais por sua altura; uma figura magra e esguia, com um olhar distante e sereno. 
A primeira conclusão tirada da educação de Paulo foi a de que ele não era alfabetizado. Ele sabia copiar as letras, mas não sabia juntá-las e formar palavras, mesmo assim, era obrigado a copiar a matéria do quadro como seus colegas. Este processo, muitíssimo lento, fazia com que na maioria das vezes a turma precisasse esperá-lo terminar de copiar para que a professora pudesse dar seguimento à aula. Sobre este assunto, Mantoan escreveu:

\section{(...) aprender a ler e a escrever constitui uma das metas mais ambicionadas pelas famílias dos alunos deficientes mentais. A entrada dessas pessoas à escola está diretamente associada à expectativa de seus pais, no sentido de que sejam diminuídas, com essas habilidades, as distâncias que separam seus filhos das pessoas normais (2001, p.42).}

Existe uma crença de que a integração e a aceitação social de um portador de necessidades especiais está intimamente ligada à capacidade de ler e escrever. Persistindo nesta idéia, acaba-se por ignorar outras habilidades daquela criança, o que em muitos casos limita e impede sua socialização e progresso educacional.

Nos trabalhos e atividades em dupla, durante o período de observação do estágio, Paulo estava sempre sozinho. Por vezes se negava a realizar a proposta, tanto só quanto acompanhado. Sem incentivo da professora, ficava alheio, disperso e o mais grave, ocioso. Por vezes dormia durante a aula e justificava dizendo estar cansado por ter que ir a duas escolas, já que freqüentava a escola especial no período inverso.

Paulo, teve diversas faltas nas aulas por motivo de saúde. Sua família ainda tenta junto aos 
médicos confirmar seu diagnóstico. 0 que se sabia até o fim do período de estágio é que, além de um quadro de déficit intelectual real bastante acentuado, Paulo sofre de Distrofia Miotônica Congênita, um mal que degenera progressivamente a musculatura causando perda dos movimentos. Ele caminha quase que normalmente, sua coordenação motora é boa com uma lentidão acentuada, mas os movimentos da língua estão bastante atrofiados, comprometendo a articulação das palavras e tornando sua fala pouco entendida, o que não o impede de se comunicar.

Na proposta de estágio apresentada na Escola Paulo Fontes, procurou-se também estabelecer relações de amizade com jovens da classe. Durante as observações notou-se uma certa distância que as crianças mantinham em relação a sua professora. Isto os impedia de estabelecer laços de afeto e conseqüentemente aumentava o desinteresse pelas aulas.

Permanecer no pátio da escola durante os intervalos de recreio foi uma das "iscas" que a estagiária utilizou para conquistar os alunos. Aos poucos, o banco onde ficava a estagiária foi se tornando ponto de encontro da turma. Os alunos aproveitavam o momento para questionar sobre as próximas propostas de aula, para contar seus feitos e compartilhar segredos. Talvez os 15 minutos mais marcantes para alguns deles, onde com toda a liberdade podiam trocar experiências com um adulto receptivo a essas trocas. Além disso, este momento auxiliou na promoção das amizades entre os próprios alunos. 0 fato de se reunirem em um mesmo ponto da escola, trocarem informações sobre um mesmo assunto, formou laços de união mais fortes entre componentes de grupos distintos da sala de aula.

A importância das amizades entre as crianças há muito tem sido reconhecida por famílias e 
educadores e constituem um tópico de pesquisa muito freqüente. As amizades desenvolvidas na infância são a base para os relacionamentos na idade adulta.

No caso das pessoas com deficiências importantes, há o que se pode chamar de negligência, por parte dos educadores, no que concerne ao desenvolvimento de amizades. Existe uma certa carência de oportunidades para relacionamentos próximos, mútuos e contínuos. Isto parece ilógico quando se pensa que as amizades para crianças com necessidades educativas especiais podem ser até mais importantes do que para outras crianças, já que aquelas apresentam maior necessidade de desenvolvimento lingüístico, cognitivo, social, sexual e acadêmico. É importante se colocar que não existem pré-requisitos de habilidades comprovadas para o desenvolvimento de amizades. O único requisito necessário é a aproximação.

Bishop (1999, p.187) diz que "o desenvolvimento de amizades requer oportunidades contínuas de interação social entre os alunos com e sem deficiência". Esta interação pode ser encorajada pelos professores e pais de alunos com NEE, criando situações em que eles possam contribuir de maneira que suas limitações não sejam evidenciadas. As oportunidades de contribuir de maneira significativa são importantes não somente para a auto-estima do aluno com uma deficiência, mas também para conquistar o respeito de seus colegas.

Estas trocas realizadas no intervalo de recreio contribuíram também para o bom andamento das aulas, pois quando dentro de sala, os alunos souberam respeitar o momento, mantendo a cumplicidade anteriormente estabelecida no pátio. 


\section{As atividades artísticas}

$\mathrm{Na}$ primeira aula do estágio curricular procurou-se determinar alguns parâmetros artísticos: música, cênicas, plásticas, dança, cinema, televisão, etc. As experiências que os próprios alunos contavam propiciaram esclarecer algumas questões que se mostravam confusas para eles, já que o termo arte se aplica a muitas coisas hoje em dia: o futebol arte, a arte da cozinha, a arte é cultura, entre outras. Para isto, ouviu-se música, relembrou-se como o cinema acontece e também as peças teatrais encenadas pelos próprios educandos em outras ocasiões, apresentou-se, ainda, livros de artes plásticas e objetos artísticos.

A partir do segundo encontro tomou-se o rumo da construção tridimensional, com muitos exemplos de imagens e peças de artes.

Nos encontros que se seguiram partiu-se para a prática. A construção de uma escultura que representasse a figura humana, utilizando sucata como material. Na primeira aula Paulo não estava presente, mas na seguinte compareceu, cheio de disposição. Logo foi providenciado a formação de um novo grupo, com alunos que haviam faltado na aula anterior. Nos primeiros instantes, Paulo permaneceu afastado do grupo e alheio a discussão que se processava quanto à forma que dariam a sua construção. Mas com um pouco de incentivo ele foi se aproximando do grupo e como num passe de mágica Paulo estava cercado por seus colegas executando uma tarefa de suma importância: sustentar o corpo da escultura enquanto os outros colavam algumas partes menores. Depois ajudou a cobri-la com jornal e também pintou a escultura com os demais.

Por menor ou menos importante que possa parecer a atividade exercida por Paulo em seu 
grupo, foi fundamental para que ele sentisse seu valor e para que os demais percebessem sua capacidade.

Uma escola só é realmente inclusiva se cada aluno, incluindo aqueles com deficiências importantes, puder participar da aprendizagem e se esforçar para atingir resultados desafiadores. Com relação aos alunos com deficiências importantes, a estrutura de planejamento do currículo deve considerar suas necessidades de aprendizagem individual, concentrando a atenção dos professores no apoio e nas adaptações necessárias para cada aluno participar plenamente da unidade e atingir seus objetivos de aprendizagem. (JORGENSEN, 1999, p.262).

Num outro momento do estágio propôs-se a construção de um móbile que representasse a pesca na região de Santo Antonio de Lisboa. Depois de um levantamento feito pelas próprias crianças, cada um desenhou um ou mais objetos ligados à pesca $\mathrm{e}$ ao pescado. Surgiram, pois, barcos, remos, peixes, siris, bóias, anzóis e afins. Paulo desenhou um barco a vela, solicitando ajuda para recortar sua figura. Depois, como os demais colegas, pintou-o e pendurou nele uma linha. Durante a montagem do móbile foi o aluno mais participante. Elegeu a tarefa de cortar as linhas que iam sendo necessárias para a construção do trabalho. De tesoura em punho, sua atenção esteve redobrada no movimento dos colegas com o carretel de linha nas mãos. Outro aluno foi responsável por cortar o arame galvanizado, outros auxiliavam na sustentação da estrutura, outros penduravam as figuras recortadas no arame e assim, de uma maneira ou de outra, todos os alunos puderam participar da elaboração de um móbile em grupo, um único trabalho realizado por toda a classe. E importante salientar que cada aluno elegeu a atividade que mais the interessou, ou a que mais 
aguçou sua curiosidade. Sem que fossem obrigados a atuar desta ou daquela maneira o trabalho fluiu com mais naturalidade. 0 papel da estagiária foi orientar os passos para que se pudesse alcançar os objetivos estabelecidos sem grandes frustrações.

Por ser o mais alto da turma, foi Paulo quem subiu na cadeira e pendurou o móbile no pátio da escola para ser apreciado por todos os colegas da escola.

Nesta simples atividade de construção de um móbile, os alunos foram colocados em contato com informações novas que puderam ser mescladas ao conhecimento que tinham de suas próprias vivências. Isto porque tiveram oportunidade de conhecer a obra do artista plástico Alexander Calder e saber que a pesca, aquela atividade que seus pais e avós praticam há muitos anos, pode vir a ser tema de uma obra de artes plásticas. Ouviram, ainda, na canção de Dorival Caymmi, as palavras: canoeiro, puxa a rede do mar, percebendo que ela também pode ser tema musical. Tiveram oportunidade de contar um pouco sobre seu cotidiano ao falar sobre os objetos ligados à pesca e o produto dela obtido. Puderam expressar-se artisticamente desenhando, pintando e construindo. Foram capazes de trabalhar em grupo, ajudando uns aos outros, raciocinando logicamente e opinando para melhor solucionar as dificuldades encontradas na elaboração da atividade. Ao fim, orgulharam-se do produto porque realmente participaram do processo. Talvez isto esteja próximo da chamada inclusão.

É claro que somente a promoção de atividades que permitam a participação de todos os alunos não fará, por si só, uma escola inclusiva. Muitos outros fatores interferem e são importantes para o andamento do processo inclusivo. Uma constante atualização na formação dos profissionais 
envolvidos é fundamental. Preparar continuamente a equipe que participa do processo de ensino e aprendizagem, assim como todos os que lidam com os educandos, mantém acesa a chama que alimenta a inclusão e permite que até mesmo os novos funcionários participem do processo. Além disso, deve-se pensar num currículo adaptado às necessidades individuais, pontuando primeiramente o que é importante a um aluno aprender. A homogeneização deve ser descartada e substituída por uma política que valorize a autoidentidade positiva, ou seja, o sentimento de valor e confiança em si mesmo.

Porém, para que tudo isso se torne realidade, faz-se necessário, em princípio, que todos os envolvidos estejam abertos a estas mudanças, receptivos e com sede de transformar a escola em que trabalham num ambiente acolhedor. É fundamental, portanto, a reunião de uma equipe com objetivos bem traçados e centrada em alcançá-los.

\section{Referências Bibliográficas}

BISHOP, K. D.; JUBALA, K. A.; STAINBACK, W.; STAINBACK, S. Promovendo Amizades. In.: STAINBACK, S. \& STAINBACK, W. (Org). Inclusão: Um Guia para Educadores. Porto Alegre: Artes Médicas Sul, 1999, p.184-198.

BRASIL. SENADO FEDERAL. A Lei de Diretrizes e Bases da Educação Nacional. Brasília, 1997.

Secretaria de Educação Fundamental. Parâmetros Curriculares Nacionais: Adaptações Curriculares / Secretaria de Educação Fundamental. Secretaria de Educação Especial. Brasília: CORDE, 1999.

JORGENSEN, C. M. Planejando Currículos Inclusivos desde o início: Estratégias e Exemplos práticos para salas de Aula do Ensino Médio. In.: STAINBACK, S. \& 
STAINBACK, W. (Org). Inclusão: Um Guia para Educadores. Porto Alegre: Artes Médicas Sul, 1999, p.335-352.

MANTOAN, Maria Teresa Égler. Compreendendo a Deficiência Mental: Novos Caminhos Educacionais. $1^{a}$ Edição. $2^{a}$ Impressão. São Paulo: Scipione, 2001.

DELACROIX, M. Canoeiro. Marcelo Delacroix.: GENS, p.2000. 1CD (ca. 39min 34s) Faixa 6 (3min 40s). Masterizado em digital. 